Results Within the 40 patients there were 23 non-suppressors (ie adherent patients) and 17 suppressors (ie non-adherent patients). With the patients using the INCA technology, the server highlighted technique errors; for example, not activating the drug blister or exhaling into the mouthpiece, as well as erratic timing issues. At subsequent follow up appointments these issues were emphasised and addressed by using patient-friendly print outs showing the usage of the inhaler, with the addition of alarm reminders and behavioural cues to encourage adherence.

Conclusion FeNO Suppression and INCA testing is an effective method of identifying and managing non-adherence with the capability of encouraging improved technique and timing also having the capability to be used as a long term behavioural assistance to adherence to ICS.

\section{P146 PRESCRIBING RESPIRATORY MEDICINES WITHOUT MAKING A DIAGNOSIS OF ASTHMA IN UK PRIMARY CARE}

${ }^{1} S$ Clayton, ${ }^{2} V$ Carter, ${ }^{1}$ W Lenney, ${ }^{3} \mathrm{D}$ Price, ${ }^{4}$ I Small, ${ }^{5} \mathrm{~J}$ Smith. ${ }^{1}$ University Hospital of North Staffordshire, North Stafforshire, UK; ${ }^{2}$ Optimum Patient Care, Cambridge, UK; ${ }^{3}$ Observational \& Pragmatic Research Institute, Singapore, Singapore; ${ }^{4}$ Peterhead Medical, Peterhead, UK; ${ }^{5}$ Brtish Lung Foundation, London, UK

\subsection{6/thoraxjin-2015-207770.283}

Introduction and objectives Despite asthma being one of the most prevalent worldwide chronic diseases, there remains a wide variation in prevalence. ${ }^{1}$ The United Kingdom's (UK) National Review of Asthma Deaths ${ }^{2}$ suggests avoidable factors play a part in as many as three-quarters of cases of asthma death. There is need to highlight and address many aspects of asthma care including the variation in diagnosis across all ages to enable appropriate treatment and improve symptom control. Here we investigate the relationship between prescribing respiratory medications and making the diagnosis of asthma, in UK primary care. Methods GP recorded data were collected from 72 UK general practices participating in the pilot British Lung Foundation asthma management program in 3 health authority areas, (two Clinical Commissioning Groups in England and one Health Board in Scotland). A retrospective analysis was undertaken of the Optimum Patient Care Research Database. This included data on child and adult patients (aged between 0 and 89) in receipt of asthma medication without a diagnosis of a chronic respiratory disease, classified by the absence of a QoF recorded asthma diagnosis. Asthma medications prescribed in the previous 12 months were identified (beta2-agonists, inhaled corticosteroids, cromones or montelukast).

Results 39,124 patients received at least one respiratory medication in the 12 months prior to data collection. Of these, 9,761 (25.0\%) had no clinical diagnosis ever recorded for asthma or COPD. 3,655 patients were prescribed 2 or more respiratory prescriptions without a coded respiratory disease and 982 patients had a lower respiratory tract infection recorded within the same period.
Conclusion These results raise concern about over and undertreatment of children and adults in whom no diagnosis of asthma or any other chronic respiratory disease has been made. It is important that future Primary Care studies highlight the importance of early accurate diagnosis before starting treatment. Also, we suggest the present UK national prevalence and morbidity data are likely to underestimate the total burden of asthma within the Primary Care setting.

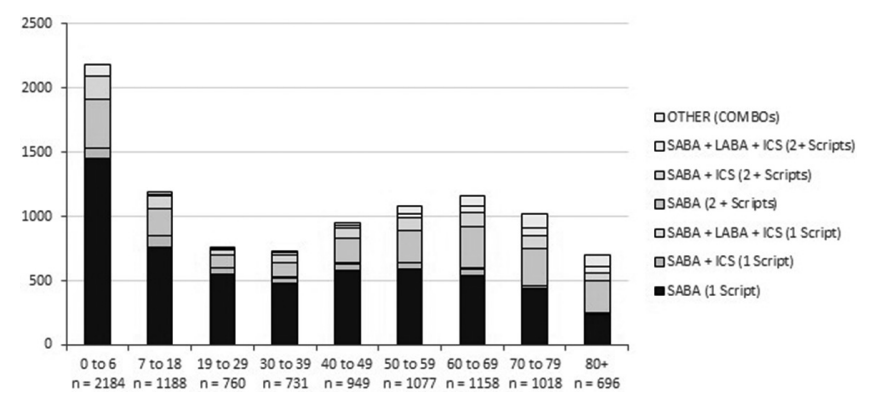

Abstract P146 Figure 1

\section{REFERENCES}

1 The NHS Atlas of Variation in Healthcare for Respiratory Disease, 2012

2 The National Review of Asthma Deaths London, NRAD, 2014

\section{P147 EVIDENCE OF MODIFIABLE PRESCRIPTION FACTORS IN PRIMARY ASTHMA CARE}

${ }^{1} \mathrm{C}$ Lewis, ${ }^{1} \mathrm{E}$ Humphreys, ${ }^{2} \mathrm{~V}$ Carter, ${ }^{2} \mathrm{~A}$ Chisholm, ${ }^{3} \mathrm{D}$ Price, ${ }^{1} \mathrm{~S}$ Walker. ${ }^{1}$ Asthma UK, London, UK; ${ }^{2}$ Optimum Patient Care, UK; ${ }^{3}$ Academic Primary Care, University of Aberdeen, UK

\subsection{6/thoraxjnl-2015-207770.284}

Background In 2014, the Royal College of Physicians published the National Review of Asthma Deaths. This confidential enquiry into 195 confirmed asthma deaths in the UK highlighted that two thirds of these deaths were associated with potentially modifiable prescription factors including excessive short-acting beta agonist (SABA) use without review and prescription of long acting beta agonists (LABA) without inhaled corticosteroids (ICS), the latter of which have been associated with higher mortality. ${ }^{1}$

Aim The aim of this project was to determine how widespread these two modifiable prescription factors are in the treatment of asthma in UK general practice.

Methods Primary Care data were obtained from the Optimum Patient Care Research Database (OPCRD). Extraction criteria included patients with a current diagnosis of asthma, at least two years of continuous medical records and at least one asthma prescription in the preceding 12 months. Those who: had a comorbid diagnosis of COPD, had received no treatment for the past 12 months and children $<4$ years of age were excluded. Asthma prescription data for the previous 12 months were extracted, and patients who had been prescribed LABAs with no ICS, or 
who had been prescribed $\geq 12$ SABA inhalers without an asthma review (as coded by QOF) were identified.

Results 94,955 asthma patients met the inclusion criteria, of which $12661(13 \%)$ were children. LABAs with no ICS had been prescribed to 402 patients $(0.4 \%)$. A total of 5032 patients (5.3\%) had been prescribed $\geq 12$ SABA inhalers, ranging from 13-136 inhalers of which 1965 (39\%) had not had an asthma review. Among these, 117 were children, $0.92 \%$ of the total. Conclusion These data, covering a large GP population, suggest evidence of non-guideline recommended prescribing which might contribute to increased risk to asthma patients. Prescribers should consider implementing system alerts to identify and review such prescribing behaviours.

\section{REFERENCE}

1 Lee C, Corren J. Budesonide/formoterol in the treatment of asthma. Expert Rev Respir Med 2008;2:551-64

\section{P148 ONCE-DAILY TIOTROPIUM RESPIMAT ${ }^{\circledR}$ ADD-ON TO AT LEAST ICS MAINTENANCE THERAPY REDUCES EXACERBATION RISK IN PATIENTS WITH UNCONTROLLED SYMPTOMATIC ASTHMA}

${ }^{1} \mathrm{D}$ Halpin, ${ }^{2} \mathrm{ED}$ Bateman, ${ }^{3} \mathrm{P}$ Paggiaro, ${ }^{4} \mathrm{ER}$ Bleecker, ${ }^{5} \mathrm{M}$ Engel, ${ }^{5} \mathrm{P}$ Moroni-Zentgraf, ${ }^{6} \mathrm{H}$ Schmidt, ${ }^{7}$ HAM Kerstiens. ${ }^{1}$ Royal Devon \& Exeter Hospital, Exeter, UK; ${ }^{2}$ University of Cape Town, Cape Town, South Africa; ${ }^{3}$ Respiratory Pathophysiology and Rehabilitation Unit, University of Pisa, Pisa, Italy; ${ }^{4}$ Center for Genomics and Personalized Medicine, Wake Forest School of Medicine, Winston-Salem, North Carolina, USA; ${ }^{5}$ TA Respiratory Diseases, Boehringer Ingelheim Pharma GmbH \& Co. KG, Ingelheim Am Rhein, Germany; ${ }^{6}$ Global Biometrics and Clinical Applications, Boehringer Ingelheim Pharma GmbH \& Co. KG, Biberach an Der Riss, Germany; 'University of Groningen, Department of Pulmonary Medicine, University Medical Center Groningen, Groningen, The Netherlands

\subsection{6/thoraxjnl-2015-207770.285}

Background A reduction in the risk of asthma exacerbation may provide improvements in clinical burden, patient experience and healthcare costs. In Phase III trials, once-daily tiotropium Respimat ${ }^{\circledR}$ add-on to at least ICS improved lung function in patients with symptomatic asthma. We investigated exacerbation risk in each trial.

Methods Five Phase III, double-blind, placebo-controlled, parallel-group trials in patients with symptomatic asthma. Patients received tiotropium Respimat ${ }^{\circledR} 5 \mu \mathrm{g}$ or placebo Respimat ${ }^{\circledR}$ each as add-on to at least ICS maintenance therapy (Table 1). Preplanned co-primary or secondary end points were time to first severe exacerbation and time to any asthma worsening.

Results Mean baseline\% of predicted FEV 1 , ACQ-7 score and ICS dose $(\mu \mathrm{g})$ were: $56.0 \pm 13.1,2.6 \pm 0.7$ and $1198 \pm 539$ in PrimoTinA-asthma ${ }^{\circledR}$ (two replicate trials); $75.1 \pm 11.5,2.2 \pm 0.5$ and $660 \pm 213$ in MezzoTinA-asthma ${ }^{\circledR}$ (two replicate trials); and $77.7 \pm 11.9,2.1 \pm 0.4$ and $381 \pm 78$ in GraziaTinA-asthma ${ }^{\circledR}$. Tiotropium Respimat ${ }^{\circledR} 5 \mu \mathrm{g}$ reduced risk of severe asthma exacerbation by at least $21 \%$ in all three severity cohorts (Table 1 ) and risk of asthma worsening versus placebo Respimat ${ }^{\circledR}$ in all trials, with a statistically significant reduction in PrimoTinA-asthma ${ }^{\circledR}$.

Conclusion Once-daily tiotropium Respimat ${ }^{\circledR} 5 \mu \mathrm{g}$ add-on to at least ICS maintenance therapy consistently reduced exacerbations across asthma severities and so may be a beneficial add-on option to reduce current and future exacerbation risk.
Abstract P148 Table 1 Risk of severe asthma exacerbation in PrimoTinA-asthma ${ }^{\circledR}$, MezzoTinA-asthma ${ }^{\circledR}$ and GraziaTinA-asthma ${ }^{\circledR}$

\begin{tabular}{|c|c|c|c|c|c|}
\hline \multirow[b]{2}{*}{ Trial } & \multirow[b]{2}{*}{ Background medication } & \multicolumn{2}{|c|}{$\begin{array}{c}\text { Severe asthma } \\
\text { exacerbations, } \\
\text { proportion of } \\
\text { patients (\%) }\end{array}$} & \multirow[b]{2}{*}{$\begin{array}{l}\mathrm{HR}^{\mathrm{a}} \\
(95 \% \mathrm{Cl})\end{array}$} & \multirow[b]{2}{*}{$\begin{array}{l}\mathrm{p} \\
\text { value }\end{array}$} \\
\hline & & $\begin{array}{l}\text { Tiotropium } \\
\text { Respimat }^{\oplus} \\
5 \mu \mathrm{g}\end{array}$ & $\begin{array}{l}\text { Placebo } \\
\text { Respimat }\end{array}$ & & \\
\hline $\begin{array}{l}\text { PrimoTinA- } \\
\text { asthma b }\end{array}$ & $\begin{array}{l}\text { ICS }+ \text { LABA ( }>800 \mu \mathrm{g} \\
\text { budesonide or equivalent) }\end{array}$ & $\begin{array}{l}122 / 453 \\
(26.9)\end{array}$ & $\begin{array}{l}149 / 454 \\
(32.8)\end{array}$ & $\begin{array}{l}0.79 \\
(0.62, \\
1.00)\end{array}$ & 0.034 \\
\hline $\begin{array}{l}\text { MezzoTinA- } \\
\text { asthma }{ }^{\circ} \mathrm{C}\end{array}$ & $\begin{array}{l}\text { ICS (400-800 } \mu \mathrm{g} \\
\text { budesonide or equivalent) }\end{array}$ & $31 / 513(6.0)$ & $\begin{array}{l}43 / 518 \\
(8.3)\end{array}$ & $\begin{array}{l}0.72 \\
(0.45, \\
1.14)\end{array}$ & 0.164 \\
\hline $\begin{array}{l}\text { GraziaTinA- } \\
\text { asthma }{ }^{\circ} d\end{array}$ & $\begin{array}{l}\text { ICS (200-400 } \mu \mathrm{g} \\
\text { budesonide or equivalent) }\end{array}$ & $1 / 151(0.7)$ & 4/151 (2.6) & $\begin{array}{l}0.25 \\
(0.03, \\
2.24)\end{array}$ & 0.216 \\
\hline
\end{tabular}

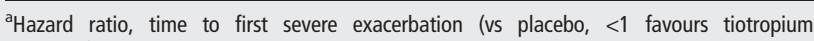

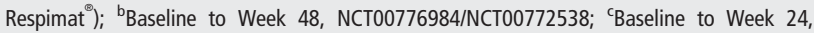

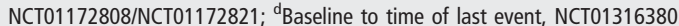

\section{P149 ONCE-DAILY TIOTROPIUM RESPIMAT ${ }^{\circledR}$ ADD-ON TO AT LEAST ICS IN ADULT PATIENTS WITH SYMPTOMATIC ASTHMA: POOLED SAFETY ANALYSIS}

${ }^{1} \mathrm{D}$ Dusser, ${ }^{2} \mathrm{R}$ Buhl, ${ }^{3} \mathrm{M}$ Castro, ${ }^{4} \mathrm{HAM}$ Kerstjens, ${ }^{5} \mathrm{P}$ Paggiaro, ${ }^{6} \mathrm{M}$ Engel, ${ }^{6} \mathrm{P}$ MoroniZentgraf, ${ }^{7} \mathrm{~A}$ Unseld, ${ }^{8} \mathrm{ED}$ Bateman. ${ }^{7}$ Pulmonary Department and Adult Cystic Fibrosis Center, Université Paris Descartes, Sorbonne Paris Cité, Cochin Hospital, AP-HP Paris, Paris, France; ${ }^{2}$ Pulmonary Department, Mainz University Hospital, Mainz, Germany; ${ }^{3}$ Division of Pulmonary and Critical Care Medicine, Washington University School of Medicine, St. Louis, Missouri, USA; ${ }^{4}$ University of Groningen, Department of Pulmonary Medicine, University Medical Center Groningen, Groningen, The Netherlands; ${ }^{5}$ Respiratory Pathophysiology and Rehabilitation Unit, University of Pisa, Pisa, Italy; ${ }^{6} T A$ Respiratory Diseases, Boehringer Ingelheim Pharma GmbH \& Co. KG, Ingelheim Am Rhein, Germany; ${ }^{7}$ Global Biometrics and Clinical Applications, Boehringer Ingelheim Pharma GmbH \& Co. KG, Biberach an Der Riss, Germany; ${ }^{8}$ Department of Medicine, University of Cape Town, Cape Town, South Africa

\subsection{6/thoraxinl-2015-207770.286}

Background A high proportion of patients with asthma are symptomatic despite at least ICS maintenance therapy. Five trials aimed to evaluate the safety of tiotropium Respimat ${ }^{\circledR}$ compared with placebo Respimat ${ }^{\circledR}$, each as add-on to at least ICS in adult patients with symptomatic asthma.

Methods Five Phase III and one Phase II randomised, doubleblind, placebo-controlled, parallel-group trials. PrimoTinAasthma ${ }^{\circledR}$ (48 weeks): tiotropium Respimat ${ }^{\circledR} 5 \mu \mathrm{g}$ add-on to ICS + LABA $(\geq 800 \mu \mathrm{g}$ budesonide or equivalent); MezzoTinAasthma ${ }^{\circledR}$ (24 weeks): tiotropium Respimat ${ }^{\circledR} 5 \mu \mathrm{g}$ or $2.5 \mu \mathrm{g}$ addon to ICS (400-800 $\mu \mathrm{g}$ budesonide or equivalent); GraziaTinAasthma ${ }^{\circledR}$ (12 weeks): tiotropium Respimat ${ }^{\circledR} 5 \mu \mathrm{g}$ or $2.5 \mu \mathrm{g}$ addon to ICS (200-400 $\mu \mathrm{g}$ budesonide or equivalent); Study 342 (16 weeks): tiotropium Respimat ${ }^{\circledR} 5 \mu \mathrm{g}$ add-on to ICS (400-800 $\mu \mathrm{g}$ budesonide or equivalent). Pooled safety data are presented.

Results 1929 patients received tiotropium Respimat ${ }^{\circledR}$ (PrimoTinA-asthma ${ }^{\circledR}, \mathrm{n}=456 ;$ MezzoTinA-asthma $^{\circledR}, \mathrm{n}=1036$; GraziaTinA-asthma $^{\circledR}, \mathrm{n}=309$; Study 342, $\mathrm{n}=128$ ). Frequency 